\title{
The Local Grape Varieties of Bulgaria
}

\author{
Anatoli lliev ${ }^{1(1)}$, Plamena Yankova ${ }^{2^{*}}$ (1) \\ ${ }^{1}$ Institute of Viticulture and Enology, 5800, Pleven, Bulgaria. \\ ${ }^{2}$ Technical University of Varna, Department of Plant Production, 9010, Varna, Bulgaria.
}

How to cite: lliev, A., \& Yankova, P. (2021). The local grape varieties of Bulgaria. Viticulture Studies (VIS), 1(1): 21 - 28. https://doi.org/10.52001/vis.2021.3

\section{Article History: \\ Received: 30.03.2021 \\ Accepted: 14.06.2021}

First online: 30.06 .2021

Corresponding Author

pl_yankova@abv.bg

\section{Keywords}

Local varieties

Gamza

Mavroud

Wide melnik vine

\begin{abstract}
A brief agrobiological and technological characterization of the red indigenous wine varieties Gamza, Mavrud and Wide Melnik is examined in this article. They belong to the Black Sea ecological-geographic group (Proles pontica Negr.). The Gamza and Mavrud varieties are late ripening, and the Wide Melnik vine variety is a very late ripening variety. The varieties described possess high fertility of replacement and dormant buds. The Gamza variety is widespread and shows the best agrobiological and technological qualities only in Central and Western Northern Bulgaria. It is sensitive to low winter temperatures and can only be grown as low-stemmed (dwarf) in these areas. The Mavrud variety is widespread and cultivated in the Plovdiv region, mainly in the Asenovgrad microdistrict, where it is zoned and shows its agrobiological and technological qualities best, and on smaller areas in the Pazardzhik and Stara Zagora regions. The grapes of the Mavroud variety are mainly used for the production of high quality dry black wines. The wines develop their qualities after 2-3 years of aging in wooden barrels. Wide Melnik variety is widespread in the southern part of the South-Western wine-growing region, where it is also zoned. It requires a high amount of vegetation temperature, develops and bears fruit well in microregions with high (above $4.000^{\circ} \mathrm{C}$ ) vegetation temperature, on hilly terrain with southern exposure and soils with light mechanical composition. It is one of the original Bulgarian varieties for the production of red wines.
\end{abstract}

\section{Introduction}

Vine is one of the most important agricultural crops for Bulgaria. Preconditions for this are the excellent climatic and soil conditions and also the gathered experience with its cultivations. Until the 60 's of the previous century the wine-growing production continued by the native varieties Pamid, Mavroud and Wide Melnik vine, cultivated in South and SouthWestern Bulgaria, Gamza in north-western Bulgaria, Dimyat in east Bulgaria and along the Black Sea coast and Muscat red in the SubBalkan valley from town of Karlovo to town of Sungurlare and at separate places in the Sredna Gora region (Radulov et al., 2004). Their wines have international popularity and acknowledgement, certain interest and preference is manifested towards them (Katerov et al., 1990). After the carried-out vine-growing zonation in the country and passing towards the industrial technologies for production of grapes, the share of the areas, occupied with native varieties after the 70's - 80's of the previous century is highly restricted. As a result of the occurred socio-economic changes in the country in the 90's of the previous century, the areas of the vineyards, including and those, occupied with native varieties, are highly reduced.

Traditional vinous varieties Cabernet Sauvignon, Merlot, Syrah, Chardonnay, Muscat Ottonel and etc. spread on the wine market on world scale widely. The consumers' interest becomes more and more increased towards the wines, which are obtained by native and newlyselected varieties. It is necessary to be given priority with the planting and cultivation of native vinous varieties of vines in order to be retrieved the authority of the Bulgarian authentically wine on the domestic and 
international market.

The purpose of the present study is presenting a brief agrobiological and technological characteristic of the most important native vinous varieties for Bulgaria.

\section{Results and Discussion}

\section{Gamza}

The word gamza originates from Arabic language and it is translated as kaprizka.

\section{Synonym}

Кадарка (Soviet Union), Kadarka (Hungary, Czechoslovakia, France), Cadarka (Romania), Skadarka (Yugoslavia), Blaue Kadarka (Austria), Mor Kadarka (Turkey) ( Figure 1A).

\section{Origin}

There are different attitudes about the origin of variety Gamza. Viala and Vermorel (1905) consider that Gamza originates from Albania. Zelenin and Mishtenko (1965) suggest that the variety originates from Albania or Asia Minor. Constantinescu et al. (1959) also reckon that Gamza is from Asia Minor. According to Csepregi and Zilai (1976) the variety originates from the Balkan Peninsula. Sirakov (1922) draws attention that Gamza is one of the oldest Bulgarian varieties. It was the most favourite variety for preparing high-quality wines. Based on the morphological characteristics and the wide distribution of the variety in Bulgaria Kirimidchi (1927), Nedelchev (1938), Katerov and Kostov (1964) suppose that the variety is of native origin.

Gamza variety belongs to the Black Sea ecological-geographic group (Proles pontica Negr.).

\section{Distribution}

Gamza is distributed in Hungary, Croatia, Serbia and in the region of Steiermark in Austria. It is a basic variety for production of red table wines in Hungary. It spreads on non-extensive areas in Ukraine, France and some regions in Asia Minor.

It is cultivated since antiquity in Bulgaria, but has local distribution. It was most widely spread in the regions of Veliko Tarnovo, Sevlievo, Svishtov, Pleven, Lovech, Vidin and etc. Pier Viala studied vine-growing of Bulgaria and gathered information from the old vine-growers about the most important varieties, cultivated by their ancestors and he observed vines of variety Gamza of age over one century.

The area relative share of Gamza variety to the total vineyard area varies significantly by years as $18.9 \%$ (1931), $11.9 \%$ (1938), $15.1 \%$ (1946), $11.6 \%$ (1955) and 6.5\% (1960). With the implementation of varieties, appropriate for stem cultivation, the area of Gamza continues to decrease. It is exclusively spread in West and Central North Bulgaria.

\section{Cluster}

The cluster is medium big between 8.6$14.2 \mathrm{~cm}$; the length varies from 10.0 up to 19.0 $\mathrm{cm}$, and the width from 5.0 up to $12.0 \mathrm{~cm}$, cylindrically-conical, usually with a wing, compact. The average weight of the cluster is from 140 up to $180 \mathrm{~g}$.

\section{Berry}

The berry is mostly medium large between 13.1-13.3 mm; the length varies from 10.5 up to $16.3 \mathrm{~mm}$, and the width from 10.2 up to $16.0 \mathrm{~mm}$, almost spherical, with the compact clusters and it is misshapen. The average weight is from 2.3 up to $2.7 \mathrm{~g}$. The pellicle is dark blue, thin, delicate, with abundant wax coating. Sometimes separate small grapes remain green. The texture of the grape is pulpy, and the taste is harmonious.

\section{Vegetation period}

Gamza variety is late ripening - the grapes ripen at the end of September and the beginning of October.

\section{Growing strength of the vines}

The vines of Gamza variety have medium growth. When they are grafted on stock Berlandieri $x$ Riparia Kober $5 \mathrm{BB}$, the growth is intensive. 


\section{Fertility and crop}

The variety has high fertility and very high crop with ground cultivation and Guyot formation. The indexes of fertility are comparatively permanent, and these of the crop vary a lot. The variety has very high fertility and crop of the shoots, developed by the main buds, and high of the replacing ones (Katerov, 1962). Significant number of racemes are developed by the replacing and sleeping buds, which determine the great recovering ability of the variety. The variety also has high fertility of the buds.

\section{Resistance to diseases}

The variety is sensitive to mildew (Erysiphe necator) and grey rot (Botrytis cinerea). During the period of the ripening with high soil and atmospheric humidity the grapes crack a lot and are damaged by grey rot - the rotting grapes are around $9 \%$. This is main disadvantage of the variety, since the crop decreases significantly and the quality of the grapes and wine worsen. According to Karadimcheva (1980), this disadvantage depends on the specific anatomic texture of the pellicle.

\section{Appropriate rootstocks}

Gamza is usually grafted on Shasla $x$ Berlandieri 41B, which induces a higher yield. When it is grafted on Rupestris du Lot the variety has looser clusters, the grapes ripen earlier and the damages of the grey rot are prevented.

\section{Response under different environmental conditions}

Gamza develops and bears fruit best in warm regions and soils with light mechanical composition and south exposure of the terrain. Hills with good air drainage are the most appropriate for that.

Gamza variety is sensitive to low winter temperatures.

Gamza may be stem cultivated on terrains, where the absolute minimum temperatures during the winter do not fall lower than $-20^{\circ} \mathrm{C}$.

\section{Mechanical composition of the grapes}

As per mechanical composition of the grapes of Gamza is a vinous variety. It is characterized by medium large clusters and grapes. The weight of the cluster varies within wide boundaries, and of the grape comparatively less. The percent of the grapes in the cluster and of the pulpy part in the grape are comparatively high. Gamza is a typical representative of the varieties with comparatively high yield of the must.

\section{Chemical composition of the must}

The grapes ripen in the first ten days of October. The technological maturity of the grapes occurs at the beginning of October.

The dynamics of the grapes ripening for three of the most typical regions show that the composition of the must is appropriate for production of quality dry wines, and in separate years of high-quality wine brands.

In the region of village of Novo Selo, region of Vidin, the accumulation of sugar in the grapes passes more intensively and the technological maturity occurs around the middle of September. Pechev (1957) determines that in this region Gamza variety reaches technological maturity around $15-20$ days earlier in comparison with other regions of the country.

By passing to stem cultivation of the variety, ripening of grapes is delayed and it rarely reaches appropriate technological maturity for obtaining quality wines.

The process of ripening and the quality of the grapes with Gamza variety mainly depends on the meteorological conditions of the year. In cold and rainy autumns, the grapes rots on a mass scale, which leads to significant destroying of the colouring substance under influence of the oxidase enzymes. This is reason for unsteadiness in the quality of the Gamza wines from the different yields.

\section{Usage of the grapes and evaluation of the production}

The grapes of Gamza variety is processed mainly for production of quality and ordinary dry red wines. A small part of the grapes is used for obtaining dessert wines and wine materials for 
naturally sparkling wines (Tsakov, 1965).

The wines of Gamza variety are characterized with bright red ruby colour and pleasant fruit flavor with typical resinous taste. They are soft, fresh and harmonious. They ripen comparatively quickly (for 1-2 years) and are appropriate for consumption while they are young.

The most appropriate regions for cultivation of Gamza variety are some of the hilly terrains of the Danube plain from village of Novo Selo, region of Vidin to Svishtov and the north slopes of the Balkan Mountains, where highquality brands of wine may be obtained with the respective technology of cultivation.

Great attention should be paid to the soils, to which the variety is very sensitive. A typical example in this respect are the three types of red table wines of Gamza variety (Kramolinska, Suhindolska and Karaysenska) in a comparatively small region of place of growth.

\section{Variations and branches}

It is determined that the variation Green Gamza (Nedelchev, 1938), remain green with great number of the berries for Gamza variety. It should not be propagated.

\section{Mavroud}

\section{Synonym}

Mavrud (Romania), Mavrudi (Greece), Mavroud (France), Kachivela, Svinarska loza, Tsiganka (Figure 1B).

\section{Origin}

There are different opinions about the origin of Mavroud variety. Vialia and Vermorel (1905) draw attention that it is cultivated in the region of Asenovgrad since antiquity.

Mavroud variety is cultivated since antiquity in the south part of Bulgaria and in the north parts of Greece. This gives us grounds to reckon that the variety originates from the central part of the Balkan Peninsula. It belongs to the Black Sea ecological-geographic group (Proles pontica Negr.).

\section{Distribution}

In Bulgaria Mavroud variety is cultivated predominantly in the region of Plovdiv, and on smaller areas in the region of Pazardzhik and Stara Zagora. It is cultivated mostly in the region of Asenovgrad, where it is attached and displays its agrobiological and technological qualities in the best way.

As of year 2010 in Bulgaria the relative share of the vine plantations with variety Mavroud is $3.6 \%$ of the total share of the areas with red vinous varieties (MAFFB, 2010).

The variety is also cultivated in the north regions of Greece.

\section{Vegetation period}

Mavroud is a late ripening red vinous variety which ripens at the beginning of October.

\section{Growing strength of the vines}

The vines of the Mavroud variety have medium growth.

\section{Fertility and crop}

With the ground cultivation and Guyot formation the variety has fertility and yield, which vary as per years. The replacing and sleeping buds have high fertility.

The indexes for fertility and yield along the length of the fruit vine-stock reach maximum values in the 10 - 15-th buds section. Mavroud variety has good fertility and by the buds, set in the limbs.

The studies of Stoev and Nikov (1956) display that the setting of the racemes with Mavroud variety begins a bit later in comparison with varieties Dimyat, Pamid and Bolgar - around the end of the blossoming $(9 . \mathrm{VI})$ the racemes are set up to the $3^{\text {th }}$ knot. To the $15^{\text {th }}$ knot the racemes are set not until the end of June. In August the racemes are differentiated well, especially in the middle or above the middle part of the shoot.

\section{Cluster}

The cluster is medium big between 10.1$15.6 \mathrm{~cm}$; the length varies from 11.0 to $22.0 \mathrm{~cm}$, 
and the width from 6.0 to $13.5 \mathrm{~cm}$; conical with wings, semi compact to compact. The average weight of the cluster is from 210 to $400 \mathrm{~g}$.

\section{Berry}

The berry is spherical, medium large to small $-12.8 / 12.3 \mathrm{~mm}$; the length varies from 10.3 to $15.0 \mathrm{~mm}$, and the width from 10.3 to $15.0 \mathrm{~mm}$. The average weight is from 1.5 to $1.7 \mathrm{~g}$. The pellicle is dark blue with abundant wax coating, medium thick and elastic. The texture of the berry is juicy, and the taste is nicely sweet.

\section{Resistance to diseases}

The variety is sensitive to mildew and oidium. The grapes are practically resistible to grey rot.

\section{Peculiarities of the cultivation}

The variety develops and bears fruit well with ground cultivation at formation single or double Guyot. The variety is sensitive to overloading.

\section{Appropriate stocks}

The variety does not have good affinity to the stocks Rupestris du Lot, Berlandieri x Riparia, Kober 5 BB and Shasla $x$ Berlandieri 41 B. M. Kondarev created the stock MK 4 by crossbreeding of Mavroud variety with the stock Rupestris du Lot. With the grafting of variety Mavroud on MK 4 are obtained up to $22 \%$ more first-class engrafted vines in comparison with the stock Shasla $\mathrm{x}$ Berlandieri $41 \mathrm{~B}$ and $18 \%$ with Berlandieri $x$ Riparia CO4. The grafted vines of the variety Mavroud on the stock MK 4 are distinguished with very good unity and strongly developed root system. The vines on the stock MK4 develop stronger in comparison with these on the stock Berlandieri x Riparia CO4.

\section{Response under different environmental conditions}

The variety is sensitive to low winter temperatures. The stems completely die at temperature $-21.5-23.0^{\circ} \mathrm{C}$. It develops and bears fruit well when it is planted on hilly terrains with south, south-eastern and south-western exposure and soils with light mechanical composition. It is sensitive to soil drought. The requirements to the ecological conditions restrict its distribution in a small region (Asenovgrad).

\section{Mechanical composition of the grapes}

Mavroud is a vinous variety as per mechanical composition of the grapes. The percent of the pellicles and seeds in the grapes is comparatively high, a precondition for obtaining extractive wines rich in phenolic substances. The theoretical yield of the must is also high.

\section{Chemical composition of the must}

The technological maturity of the grapes occurs around the middle of October. The content of sugar in the grapes varies significantly as per years and regions. The titrated acidity is comparatively high. The grapes have the highest content of sugars in the typical for the variety micro regions - Asenovgrad, Perushtitsa, Sliven and Haskovo.

With stem cultivation the grapes not always reach optimum technological maturity for obtaining of high-quality dry red wines.

\section{Usage of the grapes and evaluation of the production}

The grapes of Mavroud variety are used mainly for production of high-quality dry red wines. The wines develop their qualities after 23 year maturing in wooden casks.

\section{Variations and clones}

Mavroud variety distinguishes with great number of variations and branches. Kondarev et al. (1976) determined the following variations: Mavroud with large berries, Mavroud with small berries (Krumovski Mavroud), Mavroud with flattened berries and putting forth aments Mavroud. He selected branches Mavroud №1, Mavroud №2 and Mavroud №3 out of the variation Mavroud with large berries as per the method of the individual selection. 
Dimitrov et al. (1957) selected the branches Mavroud 101, Mavroud 108, Mavroud 113 and Mavroud 116 with research of the intervarietal diversity of the Mavroud variety. The selected branches differ in shape, structure, size of the cluster, berries and the number of seeds in the berry. Differences are determined in the millerandage of the berries, fertility and yield. On the grounds of the carried out researches the authors recommend for propagation Mavroud branch 108, which excels the rest branches by economic qualities.

The big inter-varietal diversity with Mavroud variety imposes to be carried out strict selection with the propagation and to be preferred the selected branches.

\section{Wide Melnik Vine}

\section{Synonym}

The name of the variety is connected with leaves, more particularly with its width (Figure 1C).

\section{Origin}

According to Nedelchev (1938), Katerov and Kostov (1964) Wide Melnik is a native variety. Kondarev et al. (1976) suppose that it of Thracian origin. Wide Melnik variety belongs to the Black Sea ecologically-geographical group
(Proles pontica Negr.)

\section{Distribution}

Wide Melnik variety is distributed in the south part of the south-western vine-growing region. Nedelchev (1938) reckons that it is typical for Melnik micro region. In the past the variety was mostly spread in the vicinities of town of Melnik, village of Harsovo, Kromidovo, Marikostinovo, Kanatova, Vinogradari, Mandzhovo and etc. As of 1976 the variety has occupied around $3 \%$ of the red vinous varieties area. In the Republic of Bulgaria, Wide Melnik variety has industrial distribution only in the south-western vine-growing region, where it is districted.

\section{Vegetation period}

Wide Melnik is a very late ripening variety - the grapes ripen during the first half of October.

\section{Growing strength of the vines}

The vines have medium growth. They are thick with leaves, since the leaf is big, and the shoots give many in number and strongly developed side offshoots.

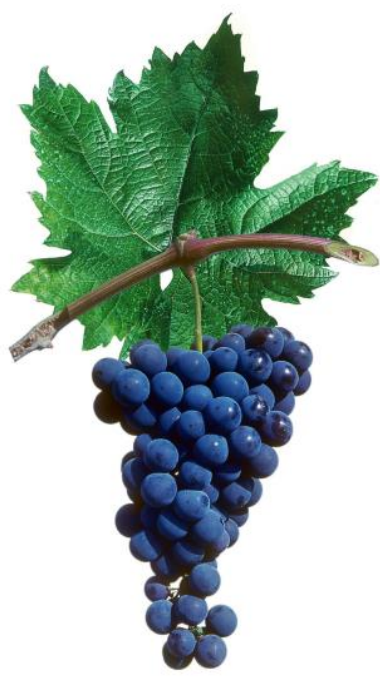

A

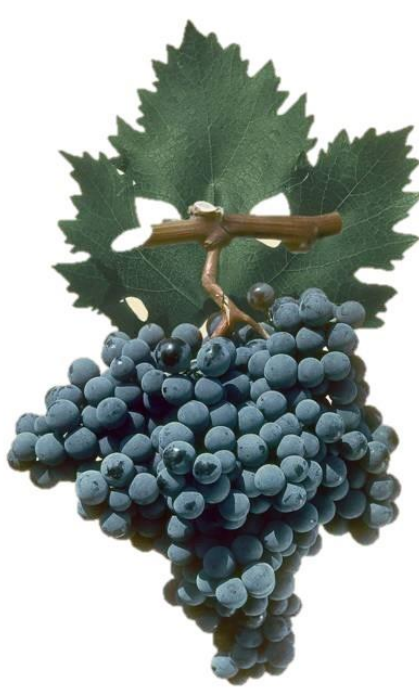

B

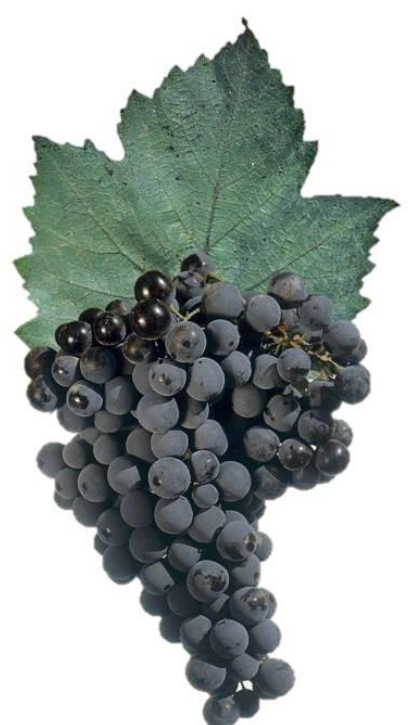

C

Figure 1. Local grape varieties of Bulgaria. 


\section{Fertility and crop}

Wide Melnik has high fertility and yield with ground cultivation and Guyot formation. The indexes of fertility and yield are comparatively permanent. The shoots, which are developed by replacing and sleeping buds are fertile. The racemes are situated from $2^{\text {nd }}$ to $7^{\text {th }}$ node of the shoot. The indexes of fertility and yield are high of the shoots by limbs, but the highest values show the shoots grown from 6 to 12 buds of the fruit vine-stock.

\section{Cluster}

The cluster is medium big to big $-9.1 / 15.2$ $\mathrm{cm}$, the length varies from 8.7 to $23.0 \mathrm{~cm}$, and the width from 5.0 to $14.3 \mathrm{~cm}$, conical, sometimes with a wing, semi compact to compact. The average weight of the cluster is from 200 to $300 \mathrm{~g}$.

\section{Berry}

The berry is oval, medium large between 12.4-13.7 $\mathrm{mm}$, the length varies from 11.0 to 16.2 $\mathrm{mm}$, and the width from 10.2 to $14.8 \mathrm{~mm}$. The pellicle is dark blue, with abundant wax coating. It is thick and elastic. The texture of the berry is juicy, and the taste is harmonious. The average weight of the berry is from 2.0 to $2.7 \mathrm{~g}$.

\section{Resistance to diseases}

The variety is sensitive to mildew and oidium. The grapes are practically resistible to grey rot.

\section{Peculiarities of cultivation}

The Guyot formation is the most appropriate for the variety or a two-side chain with short fruit-bearing sections.

\section{Appropriate stocks}

Wide Melnik variety develops and bears fruit well when it is grafted on the stock Berlandieri $x$ Riapria Kober 5 BB and $\mathrm{CO} 4$ and Shasla x Berlandieri 41B.

\section{Response under different environmental conditions}

The variety requires high amount of the vegetation temperature. It is comparatively resistible to drought. The variety is sensible to low winter temperatures. Wide Melnik develops and bears fruit well in micro regions with high (over $4.000^{\circ} \mathrm{C}$ ) vegetation temperatures on hilly terrains with south exposure and soils with light mechanical composition.

\section{Mechanical composition of the grapes}

Wide Melnik is a vinous variety as per mechanical composition of the grapes. The relative share of the hard residuum is big (18.1\%). The grapes have average to big theoretical yield of the must.

\section{Chemical composition of the must}

Researches in the region of Sandanski show that with low stem growing of the vines the grapes reach technological maturity for production of red wines as of the middle of October. With these conditions it has high content of colouring substance. With passing to high stem cultivation of the vineyards, the ripening of the grapes delays and not always reaches optimum technological maturity.

\section{Usage of the grapes and evaluation of the production}

Wide Melnik variety is one of the original Bulgarian varieties for production of red wines. The grapes are processed mainly for production of dry red and dessert wines. The table wines are alcoholic, highly extractive, very rich in phenolic substances and especially of tannin. The titrated acidity of the wines is not high because of which they are harmonious, despite the significant content of tannin. The young wines have specific for the variety pleasant fruit taste. They are very appropriate for aging in oaken casks. The old wines of Wide Melnik are characterized with beautiful - brick-red colour, soft harmonious taste and exceptionally intensive bouquet with pleasant vanilla-tobacco tones. 


\section{Variations and branches}

Kondarev et al. (1976) separated branch Wide Melnik with small berries. It differs from the main variety by the size of the cluster, by the massiveness of the berries and it has a smaller number of seeds in the berry. The vines have lower yield. The grapes accumulate more sugar (with $2 \%$ ), but it has lower titrated acidity (with $2 \%)$.

\section{Conclusion}

1. Gamza and Mavroud varieties are late ripening, and Wide Melnik vine is a very late ripening variety.

2. The described varieties have high fertility of the replacing and sleeping buds.

3. Gamza variety is wide - spread and displays best agrobiological and technological qualities only in Central and Western North Bulgaria, Mavroud variety in Plovdiv region, mainly in Asenovgrad micro region, and Wide Melnik vine variety only in south-western vinegrowing region in micro regions with vegetation temperature over $4.000{ }^{\circ} \mathrm{C}$.

\section{References}

Constantinescu, G., Negreanu, E., Lăzărescu, V., Poenaru, I., Alexei, O., \& Boureanu, C. (1959). Ampelografia Republicii Populare Romîne, Vol.II, Ed. Academiei R.P.R. Bucuresti, Romania.

Csepregi, P., \& J. Zilai. (1976). Szolofajtaink, Budapest, Mezfgazdasagi, Kiado, p. 210-211.

Dimitrov, P., Yordanov, Y., \& Katerov, K., (1957). Studies on intra-varietal diversity in the varieties Mavrud and Dimyat, NIILV, Pleven, Vol. 1, Zemizdat, p. $115-144$.

Karadimcheva, B. (1980). Morphological and anatomical features and antimicrobial properties of grapes of the cultivated vine (Vitis vinifera) in connection with its resistance to gray rot. Thesis of doctorate. Agricultural Academy, Sofia, Bulgaria.

Katerov, K., (1962). Characterization of fertility and grape yield of the introduced in Bulgaria wine varieties in comparison to the local industrial wine varieties. Proceedings of the Institute of Viticulture and Enology in Pleven, Vol. 3: 93-110 (Bg).

Katerov, K., \& P. Kostov. (1964). Catalogue of vine varieties in Bulgaria, Zemizdat, p.196.

Katerov, K., Donchev, A., Kondarev, M., Getov, G., Nachev, T., Hershkovich, E., Valchev, V., Markova, M., Braikov, D., Todorov, H.,Mamarov, P., Ivanov, J., Zankov, Z., Tsankov, B., Radulov, L., Ivanov, M., \& Zhekova, M. (1990). Bulgarian ampelography, Vol. 1, General ampelography. BAS, Sofia. Bulgaria.

Kirmidchi, N. (1927). Vine varieties in Bulgaria (Short ampelography), Lom, Zora printing house, p.105.

Kondarev, M., Kurtev, P., Tsankov, B., \& Radulov, L. (1976). Ampelography, Plovdiv, "Hr. Danov ", p. 263-265.

MAFFB. (2010). Ministry of Agriculture Food and Forestry of Bulgaria, Agrostatistics.

Nedelchev, N. (1938). Ampelography. Sofia, Profizdat, p.107-109.

Pechev, K. (1957). Technological characteristics of the Gamza variety in the area of the village of Novo Selo, Vidin region. - In: Science, Vol. 1, Sofia, Tehnika, p. 59-82.

Radulov L., P. Abrasheva, Ivanov, M. (2004). Perspective wine grape varieties for Bulgaria. Issued by Project FAMAD, $65 \mathrm{p}$.

Sirakov, G., (1922). Description of one of the best-quality local grapes, Gorna Oryahovitsa, pr. "P. Grigoriev and co", p. 24 (Bg).

Stoev, K., \& Nikov M. (1956). On some biological features in the formation and development of inflorescences and buds in the vine. - In: Ministry of Agriculture Food and Forestry of Bulgaria, Zemizdat, p. 1-16.

Tsakov, D. (1965). Study of some grape varieties for the production of wine materials and blends for naturally sparkling wines. Disertation,. Agricultural Academy, Sofia, Bulgaria.

Viala, P., \& Vermorel, V. (1905). Acipelographie, Vol. 6, Paris, Masson et Cie, Editeurs, p. 393-401.

Zelenin, I. L, \& Mishchenko, I. (1965). Kadarka.- In: Ampelography of the USSR, Vol. 2. Uncommon grape varieties, M. Pishchepromizdat, p. 10-13. 